\title{
An 89-year-old man with dysphagia due to an aortic aneurysm and enlarged left atrium
}

\author{
Ziran Meng MD, Michael Pereira MD, Aditya Sharma MD
}

Cite as: CMAJ 2020 November 23;192:E1539. doi: 10.1503/cmaj.200427

A n 89-year-old man with a history of a repaired abdominal aortic aneurysm was admitted to hospital for weight loss of $9 \mathrm{~kg}$ over the previous 6 months, which was due to progressive dysphagia to both solids and liquids. Esophagogastroduodenoscopy showed an atypical esophageal mass (Figure $1 \mathrm{~A}$ ), but suspecting possible vascular ectasia, we decided not to biopsy the lesion. Chest radiography showed cardiomegaly with left atrial enlargement (Figure 1B). Computed tomography of the chest did not show a discrete esophageal mass; however, it did show a tortuous thoracoabdominal aneurysm that measured $6.7 \mathrm{~cm}$ at the level of the hiatus and $9.5 \mathrm{~cm}$ at the level of the celiac artery. It also showed an enlarged left atrium measuring $7.8 \mathrm{~cm}$ in maximal dimension (Figure $1 \mathrm{C}$ and Appendix 1, available at www.cmaj.ca/ lookup/doi/10.1503/cmaj.200427/tab-related-content). A subsequent barium esophagram showed substantial hold up of contrast at the lower esophagus, consistent with extrinsic compression and age-related dysmotility (Figure 1D). Our patient opted for conservative management, given the substantial risks of surgical repair. We consulted with nutrition services who were able to help his dysphagia with a soft diet.

Dysphagia aortica refers to problems swallowing because of extrinsic compression of the esophagus by an enlarged aorta. Dysphagia megalatriensis refers to the external compression of the esophagus by an enlarged left atrium. Both are uncommon, and the combination, as in our patient, is rare. ${ }^{1}$ Esophagram and esophageal manometry can help with establishing the diagnosis. ${ }^{2}$ For dysphagia aortica, case reports have shown improvements with surgical repair, while for dysphagia megalatriensis, treatment of the underlying cardiac condition may improve symptoms. ${ }^{1,3,4}$ For patients who cannot tolerate surgery, treatment options include insertion of a percutaneous feeding tube or a switch to soft and minced foods. ${ }^{5}$

\section{References}

1. Choi SH, Yang G, Gagnon J. Dysphagia aortica secondary to thoracoabdominal aortic aneurysm resolved after endograft placement. J Vasc Surg Cases Innov Tech 2019;5:501-5.

2. Wilkinson JM, Euinton H, Smith L, et al. Diagnostic dilemmas in dysphagia aortica. Eur J Cardiothorac Surg 1997;11:222-7.

3. Siddiqui J, Hughes F. Dysphagia due to thoracic aortic aneurysm, relieved by thoracic endovascular aneurysm repair: a case report and review of the literature. BMJ Case Rep 2011;2011:bcr0920114793.

4. Zia HA, Madhoun M. Cardiogenic dysphagia by dysphagia megalatriensis and aortica. Clin Gastroenterol Hepatol 2020;18:e21.

5. Kim JH, Jang S, Kim D, et al. A patient with dysphagia due to an aortic aneurysm. Korean Circ J 2009;39:258-60.

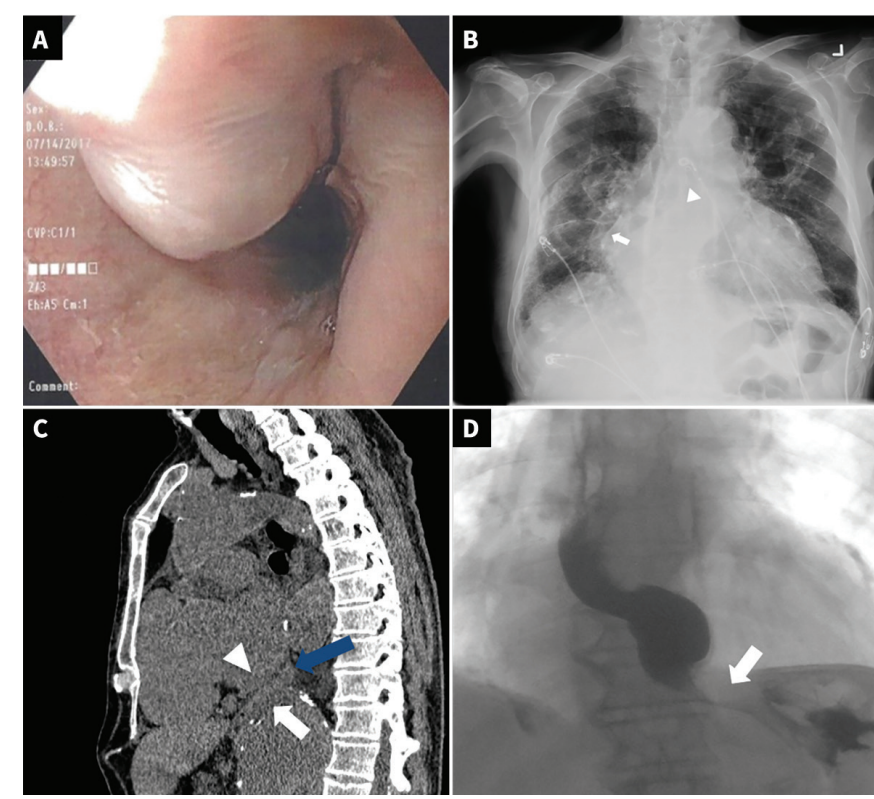

Figure 1: Test results from an 89-year-old man with progressive dysphagia and weight loss. (A) Esophagogastroduodenoscopy showing external compression of the esophageal lumen. (B) Posteroanterior chest radiograph with signs of left atrial enlargement (double-density sign [white arrow] and splaying of carina [arrowhead]). (C) Sagittal computed tomography scan showing external compression of the esophagus (blue arrow) by the left atrium (arrowhead) and aorta (white arrow). (D) Barium esophagram showing extrinsic compression at the level of the lower esophagus (white arrow).

Competing interests: None declared.

This article has been peer reviewed.

The authors have obtained consent from the next of kin.

Affiliations: Departments of Internal Medicine (Meng, Sharma) and Radiology (Pereira), University of Manitoba, Winnipeg, Man.

Correspondence to: Ziran Meng, mengz2000@gmail.com

Clinical images are chosen because they are particularly intriguing, classic or dramatic. Submissions of clear, appropriately labelled highresolution images must be accompanied by a figure caption. A brief explanation (300 words maximum) of the educational importance of the images with minimal references is required. The patient's written consent for publication must be obtained before submission. 